\title{
Industry electricity price and output elasticities for high-income and middle-income countries
}

\author{
Brantley Liddle ${ }^{1,2}$ (D) Fakhri Hasanov ${ }^{3}$
}

Received: 10 June 2020 / Accepted: 26 March 2021 / Published online: 13 April 2021

(C) The Author(s) 2021

\begin{abstract}
Energy planning and climate policy require understanding long-run energy demand patterns. Electricity demand further is important because energy services derived from electricity typically do not have substitution possibilities from other fuels. By employing dynamic panel models, we estimate the long-run price and output elasticities of aggregate industrial electricity demand for high-income (mostly OECD) and middle-income (mostly non-OECD) countries. The unbalanced data span 19782016 and include 35 high-income countries and 30 middle-income countries. Our dynamic panel estimates address nonstationarity, heterogeneity, and cross-sectional dependence. We believe these are the first such panel estimates for middle-income/ non-OECD countries and among the few such estimates for high-income/OECD countries to appear in the literature. The output elasticity for high-income countries typically was significantly below unity, around 0.5 , and the price elasticity was around -0.25 (and was statistically significant). For middle-income countries, the output elasticity was greater than unity and was likely significantly larger than the output elasticity for high-income countries, whereas the price elasticity was small and insignificant for middle-income countries.
\end{abstract}

Keywords Industrial electricity demand - OECD and non-OECD panels · Common factor panel models $\cdot$ Dynamic models

JEL classifications $\mathrm{C} 23 \cdot \mathrm{C} 50 \cdot \mathrm{Q} 41$

Brantley Liddle

btliddle@alum.mit.edu

1 Energy Studies Institute, National University Singapore, Singapore, Singapore

2 Present Address: 5604 York Lane, Bethesda, MD 20814, USA

3 King Abdullah Petroleum Studies and Research Center, Riyadh, Saudi Arabia 


\section{Introduction}

The econometric modeling of energy/electricity demand (e.g., determining income/ output and price effects) improves understanding regarding how energy/electricity consumption and its economic drivers have evolved historically, and how projections of income/output and price will shape future energy/electricity demand. Planning energy strategies and climate policy requires insights about long-run energy/ electricity demand patterns. Specifically, these insights are useful to demand-side policymakers for managing electricity consumption using tools such as energy prices, tax rates, and tariffs. These same insights are also useful to the policymakers dealing with supply and security of energy/electricity to be generated to meet the demand adequately.

The literature includes various modeling attempts to gain insights into longrun energy demand, by examining various factors that influence that demand (e.g., energy prices, income/output/value added). While there is a substantial literature applying single-equation models to estimate the long-run energy price and economic activity elasticities of residential and transport energy demand, for example, there have been very few similar studies focused on industry energy demand (and even fewer studies on industry electricity demand). Although industry energy consumption has remained fairly steady at one-third to one-quarter of total energy consumption, electricity's use in industry has increased substantially. ${ }^{1}$

The share of electricity consumption in industry's total energy consumption has been growing steadily since the 1970s, as Fig. 1 demonstrates. The figure shows the traces of electricity's share of energy consumption for OECD Asia-Oceania, OECD Europe, OECD North America (Canada and US), and for the 30 middle-income countries in our sample. The share of electricity has been growing in nearly all of the individual 30 middle-income countries (that make up our sample) as well, and has climbed to over $30 \%$ in several of them. ${ }^{2}$

Electricity also is important because industrial energy services derived from electricity typically do not have substitution possibilities from other fuels. For example, ventilation and air conditioning, lighting, cooling, and machine tool operation usually require electricity only. Indeed, Steinbuks (2012), who examined UK disaggregated manufacturing data, concluded that electricity was a poor substitute for other fuels as well, a finding that was true even for heating processes in which interfuel substitution is technologically more likely. Furthermore, electrification is key to unlocking efficiency improvements in industry, like the electric arc furnace and electric heat pumps.

We estimate price and output elasticities of aggregate industry electricity demand for panels of 35 high-income (mostly OECD) and 30 middle-income (mostly non-OECD) countries employing a heterogeneous dynamic panel estimator that

\footnotetext{
${ }^{1}$ Electricity also played a prominent role in the so-called Second Industrial Revolution, which occurred over the last quarter of the nineteenth century and the beginning of the 20th (Rosenberg 1998).

2 Those countries with a high electricity share are Chile, Ecuador, El Salvador, Guatemala, Jordan, Lebanon, Mexico, Morocco, Peru, South Africa, and Turkey.
} 


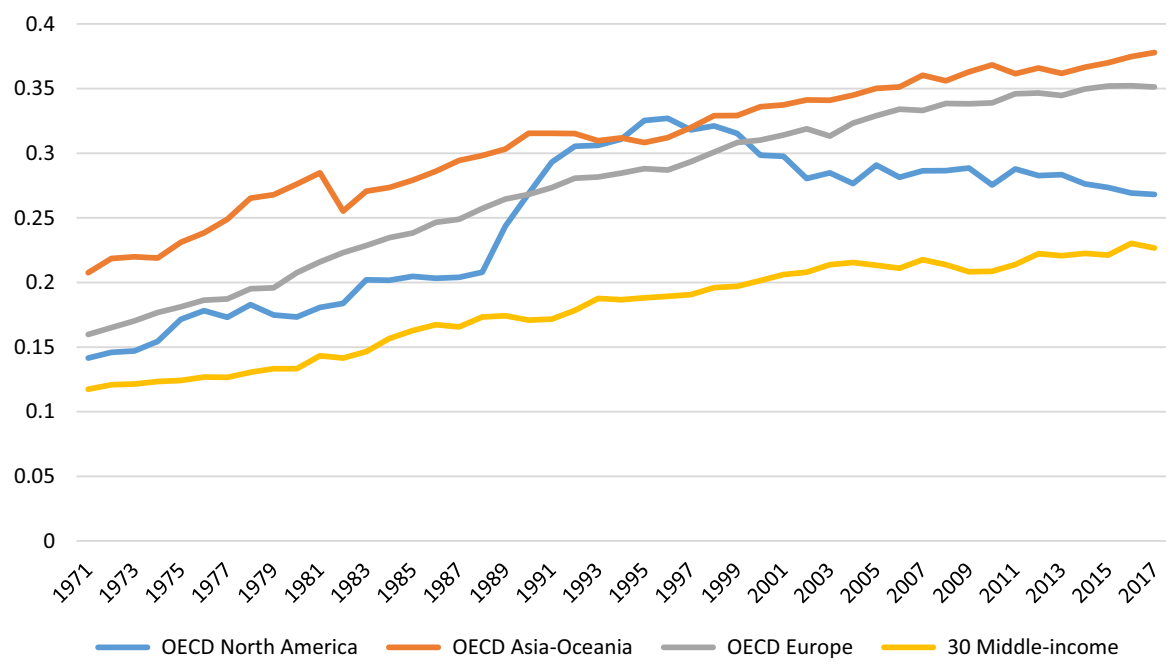

Fig. 1 Electricity's share of industry energy consumption, 1971-2017. Data from IEA's World Energy Balances. OECD Asia-Oceania includes Australia, Israel, Japan, South Korea, and New Zealand; OECD Europe excludes Turkey; OECD North America is comprised of Canada and USA; Middle-income countries are listed in Appendix Table 7 (and include Chile, Mexico, and Turkey)

addresses nonstationarity and cross-sectional dependence. Some of the earlier industry-focused literature have addressed issues like controlling for underlying forces or efficiency improvements (Dilaver and Hunt 2011), asymmetric price responses (Adeyemi and Hunt 2014), or dynamic panel bias (Cialani and Mortazavi 2018). However, that literature has mostly ignored other important issues-e.g., nonstationarity and cointegration, cross-sectional dependence, heterogeneity, and allowing for dynamics more complicated than the partial adjustment model. In addition, there has been a limited number of panel studies of aggregate industry energy/electricity consumption for OECD countries, and no such coverage for non-OECD country panels ${ }^{3}$ - with only a rather limited number of single, non-OECD country studiesbecause of a lack of energy/electricity price data for countries outside OECD/IEA.

Hence, we contribute to this literature by: (i) considering a larger high-income/ OECD panel than has been examined before, and one that focuses on industry electricity demand and estimates an industry output elasticity as opposed to considering aggregate income/GDP measures, as have previous studies; (ii) applying a more flexible dynamic model; and (iii) using methods that address heterogeneity and cross-sectional dependence and thereby account for both (a) unobserved factors that commonly affect the panel members and (b) country-specific factors that make each panel member different from other members. Moreover, for the first time we present

\footnotetext{
${ }^{3}$ Van Benthem and Romani (2009) do analyze a panel of 17 mostly non-OECD countries and appear to consider both industry energy consumption and an index of end-use industry energy price. But they include (a polynomial of) GDP per capita, and thus, their estimations are not of an industry demand function per se.
} 
estimates of price and output elasticities of industry electricity based on a panel of middle-income, mostly non-OECD countries, roughly three-quarters-to-half of which, to our knowledge, have never been analyzed before (even in a single country setting). So, for the first time to our knowledge, we are able to answer the question: whether industry price and output elasticities differ between high-income/OECD and middle-income/non-OECD countries and, if so, by how much ${ }^{4}$ In addition, we derived policy insights from our findings to inform demand-side management, supply-side planning, and environmental aspects of industrial electricity consumption.

\section{Literature review}

We surveyed papers that investigated the effects of both output and price on industrial energy/electricity demand at the aggregate (rather than firm) level. While there have been several single country OECD estimates (particularly so for UK and US), we concentrate our review on OECD panel analyses. Hence, we first grouped papers that considered cross-national (as opposed to inter-state/province) panels, and we summarized such studies in Table 1. Next, since there have been relatively few papers that focused on analyzing output and price elasticities of industry electricity/ energy demand in non-OECD countries (effectively no panels, only single country studies), we summarized these (single-country) papers in Table 2 and discuss them briefly below as well. In other words, we have attempted to produce a more or less exhaustive list of OECD panel studies and single-country non-OECD studies.

We focus on the long-run estimations of the elasticities. However, many papers that employed a dynamic model did not report the statistical significance of their long-run estimations; yet, they did report the significance of their short-run estimations, and so, from those reported statistics we can surmise the likely significance of the long-run estimations.

Industry energy, cross-national panel estimations of price and output elasticities have focused on OECD/European panels as outlined in Table 1. All five of these cross-national panel analyses have used the less flexible dynamic partial adjustment model, have employed methods that did not address cross-sectional dependence, and were homogeneous. They also did not address nonstationarity and cointegration properties of the data used. ${ }^{5}$ (These omissions are despite the fact that four of the five papers are rather recent.)

\footnotetext{
${ }^{4}$ In addition to the absence of previous non-OECD panel analyses, even meta-studies, like Labandeira et al. (2017), do not appear to have the resolution/available data to determine whether/how much elasticities vary between OECD and non-OECD countries at the industry sectoral level.

5 The preferred estimator of Csereklyei (2020)_between effects (BE) — essentially estimates a static, cross-section. However, there is some evidence that $\mathrm{BE}$ is robust to nonstationarity, and possibly, cointegration (e.g., Pesaran and Smith 1995). Adeyemi and Hunt (2007) considered only nonstationarity but not cointegration properties of their variables. Moreover, they performed unit root tests only for the industrial energy demand but not for price and income variables. Lastly, they used only the first-generation panel unit root tests, which do not account for cross-sectional dependency that most likely exists in the data used.
} 


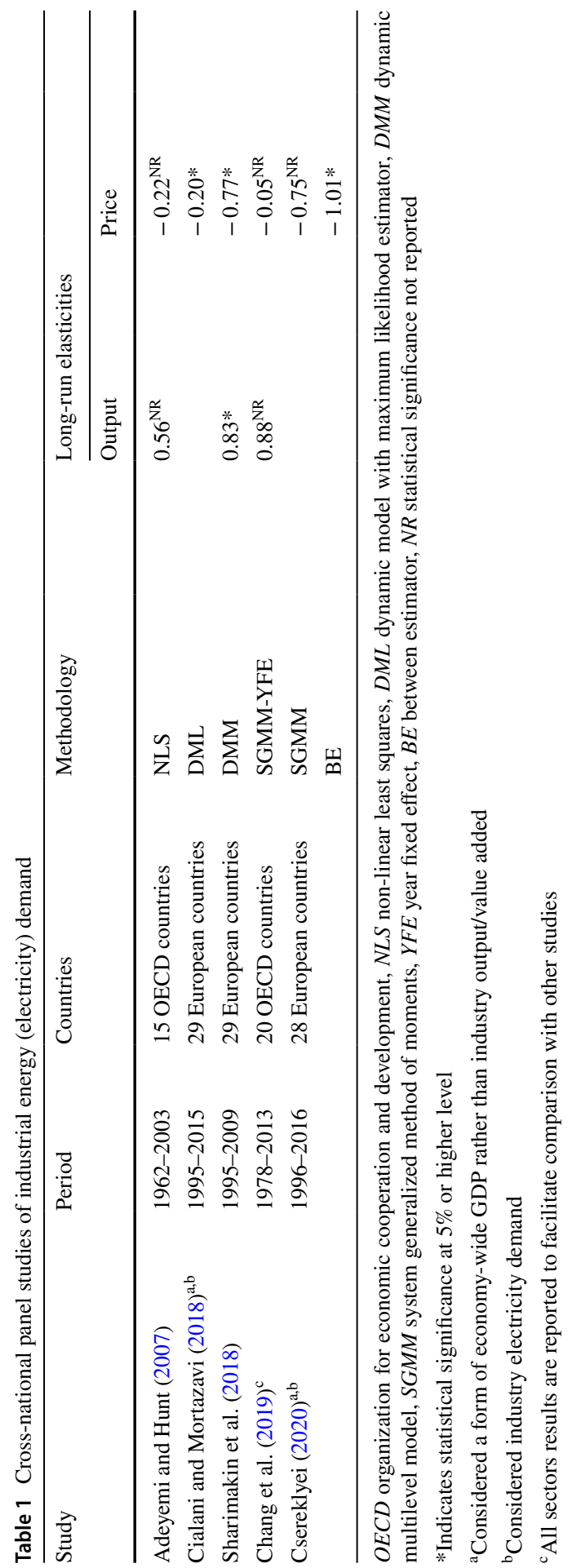


Table 2 Individual non-OECD country studies of industrial electricity (or energy) demand

\begin{tabular}{|c|c|c|c|c|c|}
\hline \multirow[t]{2}{*}{ Study } & \multirow[t]{2}{*}{ Period } & \multirow[t]{2}{*}{ Country } & \multirow[t]{2}{*}{ Method } & \multicolumn{2}{|c|}{$\begin{array}{l}\text { Long-run elastici- } \\
\text { ties }\end{array}$} \\
\hline & & & & Output & Price \\
\hline El-Shazly (2013) & $1982-2010$ & Egypt & DOLS, AR(2) & $1.33 * *$ & $0.05^{\mathrm{NS}}$ \\
\hline Bose and Shukla (1999) & 1985-1994 & India & OLS & $0.73 * *$ & $-0.04^{\mathrm{NS}}$ \\
\hline Shirani-Fakhr et al. $(2015)^{\mathrm{a}}$ & 2000-2011 & Iran & STSM & $0.85^{\mathrm{NR}}$ & $-0.47^{\mathrm{NR}}$ \\
\hline Campbell (2018) & 1970-2014 & Jamaica & ARDL & $1.22 * *$ & $-0.25^{*}$ \\
\hline Khan and Qayyum (2009) & 1970-2006 & Pakistan & ARDL & $0.50^{\mathrm{NS}}$ & $-0.87 *$ \\
\hline Jamil and Ahmad (2010) & 1960-2008 & Pakistan & VECM & $0.42 * *$ & $0.17^{\mathrm{NS}}$ \\
\hline Alter and Syed (2011) & 1970-2010 & Pakistan & VECM & $1.04 * *$ & $-0.56^{* *}$ \\
\hline Jamil and Ahmad (2011) & 1970-2008 & Pakistan & VECM & $1.61 * *$ & $-1.22 * *$ \\
\hline Javid and Qayyum (2014) & 1972-2012 & Pakistan & STSM & $1.29^{\mathrm{NR}}$ & $0.21^{\mathrm{NR}}$ \\
\hline Al-Arenan et al. (2020) ${ }^{b}$ & 1986-2015 & Saudi Arabia & STSM & $0.60^{\mathrm{NR}}$ & $-0.34^{\mathrm{NR}}$ \\
\hline Hasanov (2019) & 1984-2016 & Saudi Arabia & ARDL & $0.21 * *$ & $-0.09 *$ \\
\hline Inglesi-Lotz and Blignaut (2011) & 1993-2006 & South Africa & SUR & $0.71 * *$ & $-0.87 * *$ \\
\hline Dilaver and Hunt (2011) ${ }^{b}$ & 1960-2008 & Turkey & STSM & $0.15^{* *}$ & $-0.16^{* *}$ \\
\hline Arisoy and Ozturk (2014) & 1960-2008 & Turkey & TVPKF & $0.98 * *$ & $-0.01 * *$ \\
\hline
\end{tabular}

A analyzed quarterly data

${ }^{\mathrm{B}}$ dependent variable was industry energy consumption

$*$ and $* *$ indicate $10 \%$ significance level and 5\% and higher significance levels, respectively

$N R$ statistical significance not reported, $N S$ not statistically significant, $O L S$ ordinary least squares, DOLS dynamic OLS, AR autoregressive, STSM structural time series model, ARDL autoregressive distributed lags bounds testing approach, VECM vector error correction model, SUR seemingly unrelated regression; TVPKF time varying parameter based of Kalman filter method

Adeyemi and Hunt (2007) estimated long-run output and price elasticities of 0.56 and -0.22 , respectively, for a panel of 15 OECD countries. Given that the short-run estimate for price was highly insignificant ( $t$-value below 0.7 ), the longrun estimate was likely insignificant as well. (In a separate regression, Adeyemi and Hunt allowed for asymmetric responses to price changes, and some of those coefficients were statistically significant.)

Chang et al. (2019) considered a panel of 20 OECD countries and 16 industry sectors. They reported long-run output and price elasticities of 0.88 and -0.05 , respectively, for their full panel and preferred specification. In addition, Chang et al. estimated elasticities for a panel of the five most energy intensive sectors and a panel of the remaining less energy intensive sectors. Their long-run results suggested that energy-intensive sectors have larger output elasticities of energy demand than do less-intensive sectors: 1.23 compared to 0.48 , respectively. But energy-intensive sectors are less price sensitive than less-energy-intensive sectors, i.e., they calculated long-run price elasticities of -0.13 and -0.23 for the intensive and less-intensive panels, respectively. All three long-run price elasticities were likely insignificant since the short-run price elasticities were highly insignificant. 
Sharimakin et al. (2018) estimated industrial energy demand for 29 European countries over 1995-2009. Their long-run panel elasticities for output and price of 0.83 and -0.77 , respectively, are relatively large compared to the previous two studies (at least their price elasticity is large in absolute terms). The methodology they employed, Multilevel Data Structures Modeling, while common in several disciplines (e.g., political science, education, and health), ${ }^{6}$ has rarely been applied in energy demand modeling. One obvious reason for its lack of use in energy demand is that the highly data dependent method requires having sufficient sample size at all levels of hierarchy to satisfy size and power conditions (other issues are (i) being less robust and (ii) being more specification sensitive; see, e.g., Gelman 2006; Ponce 2013).

The only panel industry aggregate/country electricity demand studies we know of are Cialani and Mortazavi (2018) and Csereklyei (2020), who considered nearly identical panels of European countries. Cialani and Mortazavi estimated a statistically significant long-run price elasticity for industrial electricity of -0.2 ; however, they did not estimate an industry output elasticity (but rather, included economywide GDP in the regression, making that coefficient difficult to interpret in terms of industry electricity demand). Csereklyei estimated considerably higher price elasticities of between -0.75 and -1.0 , depending on method, ${ }^{7}$ and similarly, did not estimate an industry output elasticity (but rather, considered economy-wide GDP per capita).

While not a panel analysis, per se, Adeyemi and Hunt (2014) estimated industry energy consumption elasticities for 15 OECD countries individually. Their output elasticity estimates ranged from 0.3 to 0.96 with an average of 0.6 . Rather than estimate a single price elasticity, Adeyemi and Hunt (2014) were interested in asymmetric price responses and uncovered substantial heterogeneity among the OECD countries in that regard.

Table 2 displays the results for the non-OECD industry studies we found (all single-country, and all but two focused on electricity). The countries analyzed skewed towards West and South Asia, with several countries examined more than once (and they considered only eight different countries in total). The estimated elasticities for both output and price varied considerably-from insignificant to small and significant to relatively large and significant (in absolute value) — and that variation occurred among the studies that examined the same country (and, sometimes, by the same authors), as well as for the table as a whole.

Thus, it appears we have very little understanding of the price and output elasticities for aggregate industry electricity/energy consumption for non-OECD countries and a limited appreciation for those elasticities for OECD countries; such understanding is particularly limited at an electricity panel level, with only two highly

\footnotetext{
${ }^{6}$ Some examples of multilevel modeling in those disciplines are Steenbergen and Jones (2002), Ronfeldt et al. (2013) and Islam et al. (2006).

7 Csereklyei estimated a lower price elasticity of -0.4 when employing System Generalized Method of Moments (SGMM) with a time trend, but this does not appear to be Csereklyei's preferred SGMM estimation.
} 
Table 3 Summary statistics for regression data, high-income and middle-income panels

\begin{tabular}{lllll}
\hline Variable & Mean & SD & Min & Max \\
\hline & High-income $(35$ countries $)$ & & \\
VA (2010 USD) & $2.59 \times 10^{11}$ & $4.95 \times 10^{11}$ & $8.51 \times 10^{8}$ & $3.25 \times 10^{12}$ \\
Electricity (Mtoe) & 7.24 & 14.24 & 0.018 & 98.22 \\
Price (2015 US cents/kWh) & 10.67 & 3.93 & 2.80 & 30.44 \\
& Middle-income $(30$ countries) & & \\
VA (2010 USD) & $9.22 \times 10^{10}$ & $1.22 \times 10^{11}$ & $1.16 \times 10^{9}$ & $7.13 \times 10^{11}$ \\
Electricity (Mtoe) & 2.92 & 4.89 & 0.018 & 41.08 \\
Price (2015 US cents/kWh) & 12.05 & 10.90 & 0.96 & 187.58 \\
\hline
\end{tabular}

divergent panel industry price estimates for electricity demand and no panel industry output estimates for electricity demand.

\section{Data}

Both electricity price for industry (in 2015 US cents per kilowatt hour) and electricity final consumption for industry (in Mtoe) are from Enerdata's Global Energy and $\mathrm{CO}_{2}$ database. ${ }^{8}$ The price data begin in 1978. Energy price data-particularly for non-OECD countries - can be challenging to assemble (almost certainly a reason for the dearth of non-OECD analyses). The price series have been expanded/enhanced by using a real electricity price index from Pesaran et al. (1998) for Indonesia, India, and Taiwan, and by using a real electricity price index for industry from IEA for several IEA countries.

Real industry value added (in constant 2010 USD) was compiled from several sources (i.e., IEA, OECD, World Bank, and national statistical agencies). Observations for both electricity prices and value added are unbalanced. The unbalanced data span 1978-2016 and include 35 high-income (mostly OECD) countries and 30 middle-income (mostly non-OECD) countries; those countries and their data coverage are summarized in Appendix Table 7.

Table 3 reports summary statistics-displayed separately for the high-income and middle-income panels. The mean electricity price is actually slightly higher for the middle-income panel, but the spread of prices is much larger for that group than for the high-income countries. Calculating the average electricity intensity of each group-by dividing the mean of electricity consumption by the mean of value added-suggests that industry is about $13 \%$ more electricity intensive on average in the middle-income countries than in the high-income countries.

\footnotetext{
${ }^{8}$ Enerdata Global Energy \& $\mathrm{CO}_{2}$ database. https://www.enerdata.net/research/energy-market-data-co2emissions-database.html
} 


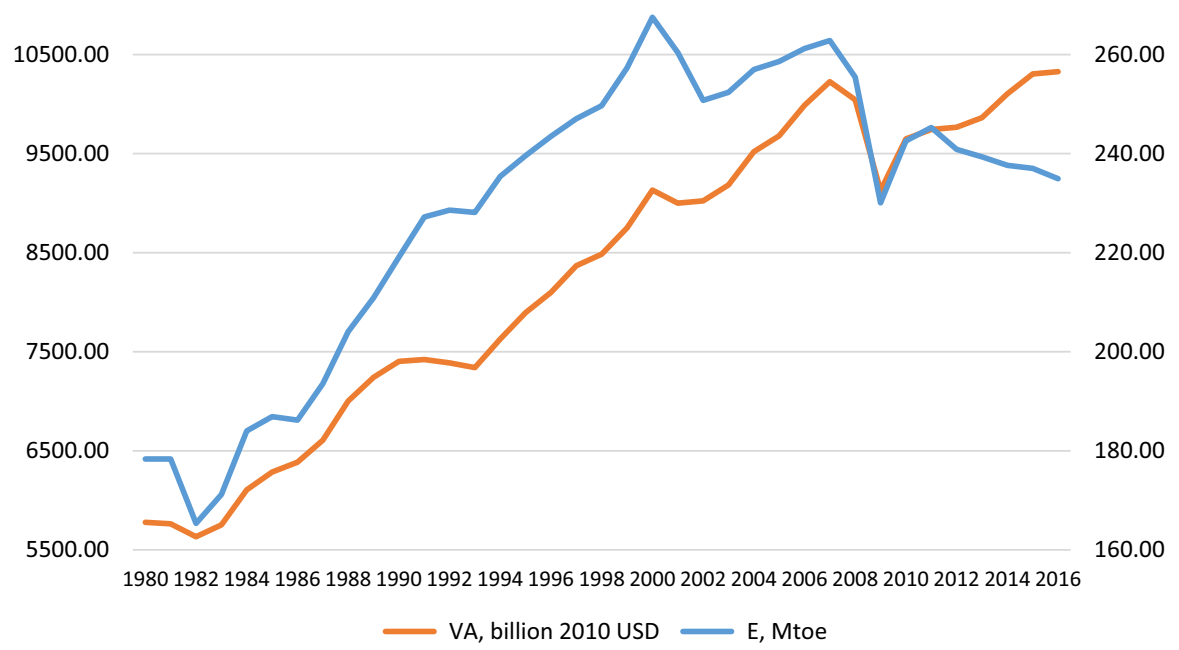

Fig. 2 Industry value added (VA) and electricity consumption $(E)$ are shown (on the left and right $y$-axes, respectively) for a balanced panel of 27 high-income (mostly OECD) countries over 1980-2016

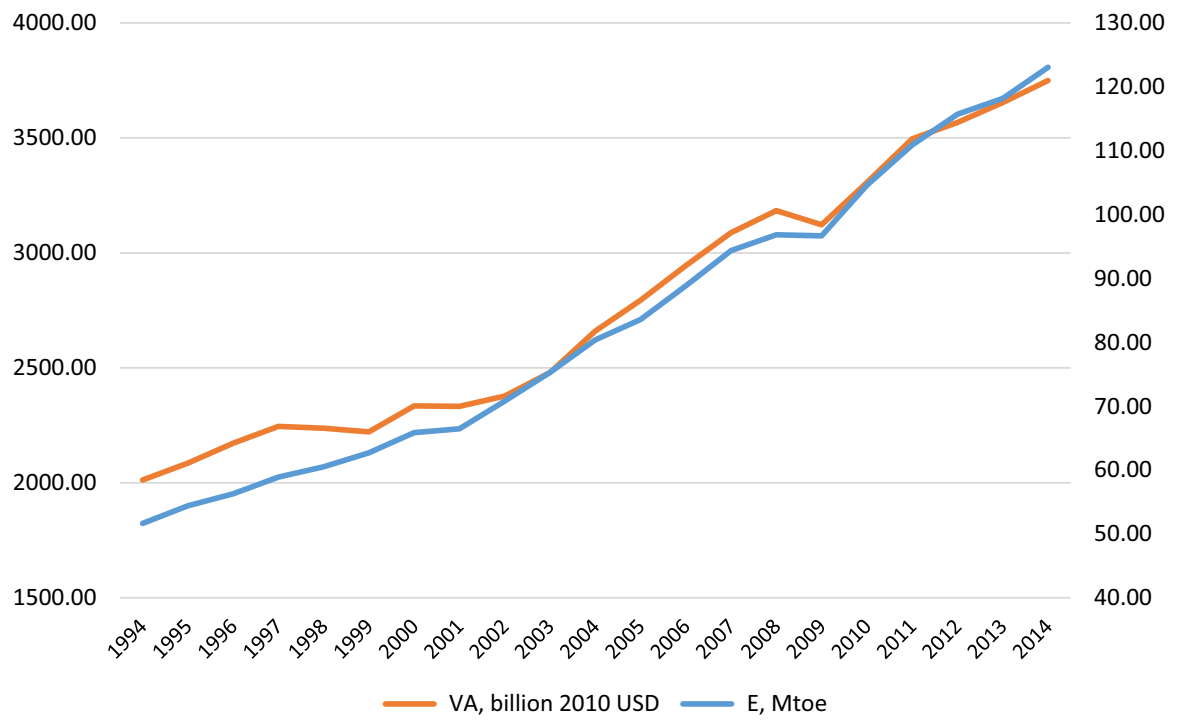

Fig. 3 Industry value added (VA) and electricity consumption $(E)$ are shown (on the left and right $y$-axes, respectively) for a balanced panel of 30 middle-income (mostly Non-OECD) countries over 1994-2014

Figures 2 and 3 display balanced (aggregate) data for high-income and middle-income countries covering the periods 1980-2016 and 1994-2014, respectively. Both figures illustrate that industrial electricity consumption has closely followed industrial value added for most of those periods - this is particularly so 


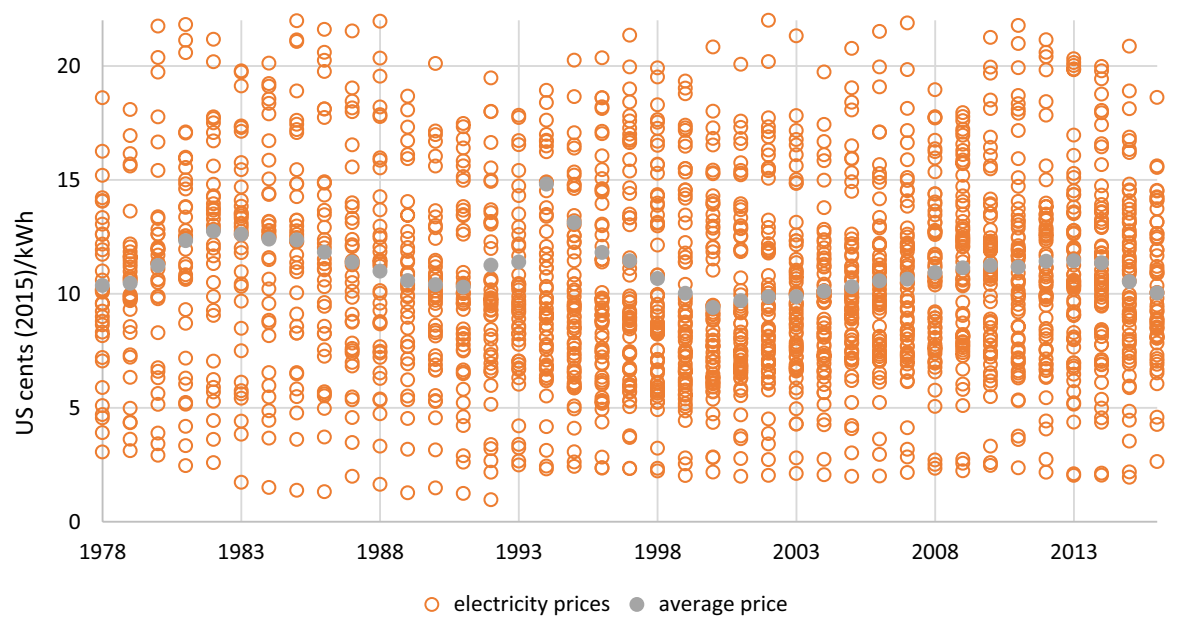

Fig. 4 Industry electricity prices (in 2015 US cents/kWh) for 65 countries over 1978-2016. The average price for each year is displayed with solid fill

for middle-income countries (Fig. 3). However, for the high-income countries (Fig. 2), consumption and value added have moved in opposite directions since 2011.

High-income industrial electricity consumption grew from 178.4 Mtoe in 1980 to 234.9 Mtoe in 2016-a compounded annual growth rate of $0.8 \%$, whereas industrial value added increased from 5.8 trillion 2010 USD in 1980 to 10.3 trillion 2010 USD in 2016 - a compounded annual growth rate of $1.6 \%$. These compounded annual growth rates were several times higher for middleincome countries-i.e., $4.4 \%$ for industrial electricity consumption and $3.2 \%$ for industrial value added over 1994-2014. Despite the large differences in compounded annual growth rates between the two sets of countries, total industrial electricity consumption and value added for middle-income countries was half or less than that compared to high-income countries in 2014.

While several manufacturing sectors are known to be energy intensivepulp and paper, chemicals, non-metallic minerals (e.g., glass, cement), iron and steel, and non-ferrous metals (e.g., aluminum smelting)—only non-ferrous metals are also electricity intensive, i.e., electricity comprises over half of the sector's energy consumption. For those other four sectors, electricity's share of energy consumption is similar to industry's overall share (at least for OECD countries). The share of industry electricity consumption for sectors that are non-energy intensive (e.g., transport equipment, machinery, wood products) ranges from $30-40 \%$ for OECD countries, but is considerably higher for middle-income countries at closer to $60 \%$. However, in OECD countries, these nonenergy-intensive sectors have become more electricity intensive since electricity's share of energy consumption in these sectors has increased to over $40 \%$ for OECD North America and Europe and to $60 \%$ for OECD Asia-Oceana. So, the importance of electricity in industry is a combination of industry structure (i.e., 
Table 4 Pesaran (2015) CD test and Correlation Coefficients, 65 Countries, unbalanced

\begin{tabular}{llll}
\hline Variables & CD-test & Corr. coeff & Abs. corr. coeff \\
\hline $\ln$ VA & $163^{*}$ & 0.67 & 0.75 \\
$\ln E$ & $113^{*}$ & 0.46 & 0.64 \\
$\ln$ Price & $32^{*}$ & 0.13 & 0.41 \\
\hline
\end{tabular}

$* p$-value $<0.001$. Corr. coeff. $=$ mean correlation coefficient; Abs. corr. coeff. $=$ mean absolute vale correlation coefficient. Null hypothesis is weak cross-sectional dependence

energy-intensive sectors vs. non-energy-intensive sectors) and the extent of electrification in industry (i.e., electricity's share of the energy mix in any particular sector).

Figure 4 shows the industry electricity prices for the 65 countries over 1978-2016 (in 2015 US cents/kWh). The figure illustrates the substantial disparity in yearly electricity prices for the individual countries (i.e., the empty circles). Indeed, any given year, countries can experience very different prices from the global average (the filled in circle). This yearly cross-country range is very large relative to the variation over time of the average price for all countries.

For the variables we consider, cross-sectional correlation/dependence is expected because of, for example, regional and macroeconomic linkages that manifest themselves through (i) global shocks (income/prices); (ii) institutional memberships like OECD and World Trade Organization; and (iii) technology transfer. The results of the Pesaran (2015) cross-sectional dependence (CD) test, ${ }^{9}$ which employs the correlation coefficients between the time-series for each panel member, are shown in Table 4. For all three variables, the test rejected the null hypothesis of weak cross-sectional dependence at the highest level of significance. For each variable considered, the absolute value mean correlation coefficients ranged from 0.4 to 0.75 (see Table 4). The difference between the absolute value mean correlation coefficient and the mean correlation coefficient suggests that for prices, some of the correlations are negative (as well as positive), but output and electricity consumption tend to move in concert among the countries.

Recently, Pesaran (2015) argued that when the number of cross-sections is large, the null hypothesis of independence is extreme, and a null of weak crosssectional dependence is more appropriate. Furthermore, Pesaran argued that cross-sectional dependence is a concern when it is pervasive (across the panel members) and of the strong form (i.e., caused by common shocks or trends), but weak cross-sectional dependence does not pose serious issues. When the errors of panel regressions are strongly cross-sectionally correlated, standard estimation methods can produce both inconsistent parameter estimates and incorrect inferences (Baltagi and Pesaran 2007; Kapetanios et al. 2011; Pesaran 2015). Thus, because cross-sectional dependence can impart bias problems as well as

\footnotetext{
9 This test is implemented via the Stata command xtcd, which was developed by Markus Eberhardt.
} 
Table 5 Pesaran (2007) CIPS Panel Unit Root Test Results, 65 Countries, unbalanced

\begin{tabular}{llllllll}
\hline Variables & \multicolumn{3}{l}{ Constant without trend } & & \multicolumn{2}{l}{ Constant with trend } \\
\cline { 2 - 3 } \cline { 7 - 8 } & \multicolumn{3}{l}{ Number of lags } & & & & \\
\cline { 2 - 3 } & 0 & 1 & 2 & 0 & 1 & 2 \\
\hline $\ln$ VA & 1.000 & 1.000 & 1.000 & 0.995 & 0.009 & 0.829 \\
$\ln E$ & 0.998 & 0.984 & 0.994 & 1.000 & 1.000 & 1.000 \\
$\ln$ Price & 0.066 & 0.139 & 0.387 & 0.943 & 0.896 & 0.995 \\
$\Delta \ln$ VA & 0.000 & 0.000 & 0.000 & 0.000 & 0.000 & 0.000 \\
$\Delta \ln E$ & 0.000 & 0.000 & 0.000 & 0.000 & 0.000 & 0.000 \\
$\Delta \ln$ Price & 0.000 & 0.000 & 0.000 & 0.000 & 0.000 & 0.000 \\
\hline
\end{tabular}

$p$-values shown. Null hypothesis is the series is I(1). Version of CIPS test used does not allow country-specific lag structure. A version of IPS test that does so suggested that panel average optimal number of lags was between 0.26 and 1.12 (depending on variable and AIC vs. $\mathrm{BIC)}$

inefficiency, only making adjustments to the standard errors (e.g., via Driscoll and Kraay 1998) may not be sufficient.

The variables analyzed are also trending and may be nonstationary-in other words, their mean and/or variance might change over time. The Pesaran (2007) panel unit root test for heterogeneous panels (CIPS), which allows for crosssectional dependence to be caused by a single (unobserved) common factor, ${ }^{10}$ suggests that the variables are likely nonstationary in levels, but stationary in first differences-see Table 5. When ordinary least squares (OLS) regressions are performed on time-series (or on time-series cross-sectional) variables that are not stationary, then measures like $R$-squared and $t$-statistics are unreliable, and there is a serious risk of the estimated relationships being spurious if the regression residuals are not stationary (Kao 1999; Beck 2008; Enders 2015).

Lags are added to unit root tests to correct for potential serial correlation. The version of the CIPS test that we run does not allow for heterogenous lag structure. So to frame the optimal numbers of lags, we first run a procedure that determines the number of lags for each panel member that minimizes either the AIC or BIC in a panel ADF regression. The panel average number of lags chosen ranged from 0.26 to 1.12 ; hence, for robustness we report results for (homogenous) panel lags of 0-2.

\footnotetext{
${ }^{10}$ This test is implemented via the Stata command pescadf, which was developed by Piotr Lewandowski.
} 


\section{Model and methods}

Following previous industry panel analyses (e.g., Adeyemi and Hunt 2007; Chang et al. 2019), we model industry electricity consumption as a function of energy price and industry output. ${ }^{11}$ Adeyemi and Hunt (2007) noted that the single equation, log-linear functional form has become standard in energy demand modeling. Further, Pesaran et al. (1998) claimed that this approach typically outperforms more complex specifications. Further still, to incorporate the gradual adjustments imposed by new capital/technology gradually replacing older vintages, we consider a dynamic, adjustment model whereby the lag of the dependent variable (electricity consumption) is included on the right-hand-side along with industrial output/value added, energy price, and their one period lags (short-hand notation, ARDL $(1,1,1)$ ):

$$
\ln E_{i t}=\alpha_{i}+\gamma_{t}+\beta_{i}^{1} \ln \mathrm{VA}_{i t}+\beta_{i}^{2} \ln \text { price }_{i t}+\beta_{i}^{3} \ln \mathrm{VA}_{i t-1}+\beta_{i}^{4} \ln \text { price }_{i t-1}+\beta_{i}^{5} \ln E_{i t-1}+\varepsilon_{i t}
$$

where subscripts $i t$ denote the $i$ th cross section and $t$ th time period, $E$ is total final electricity consumption for industry, VA is real value added for industry, and price is the real electricity price for industry, $\alpha$ is a cross-sectional specific constant, $\gamma$ are common time effects, the $\beta$ s are (potentially) cross-sectional specific coefficients to be estimated, and $\varepsilon$ is the error term. So, the long-run value added and price elasticities, respectively, are:

$$
\frac{\beta^{1}+\beta^{3}}{\left(1-\beta^{5}\right)} \text { and } \frac{\beta^{2}+\beta^{4}}{\left(1-\beta^{5}\right)}
$$

Another popular model in the literature is the partial adjustment modelARDL $(1,0,0)$-where only the dependent variable (electricity consumption) is lagged. In this case, the long-run elasticities would differ from Eq. (2) in that there would be no $\beta^{3}$ and $\beta^{4}$ terms.

We believe it is likely that the elasticities will not be the same for each country-i.e., there should be a substantial degree of heterogeneity. And if one mistakenly assumes that parameters are homogeneous (when the true coefficients of a dynamic panel in fact are heterogeneous), then all parameter estimates of the panel will be inconsistent (Pesaran and Smith 1995). Hence, we use a mean group estimator (MG) that first estimates cross-sectional specific regressions and then averages those estimated individual-country coefficients to arrive at panel coefficients (standard errors are constructed nonparametrically as described in Pesaran and Smith 1995).

\footnotetext{
11 If we were employing a pure time series approach, rather than an (unbalanced) panel approach, we would consider a more comprehensive model, as in Hasanov and Mikayilov (2020), rather than a reduced form model.
} 
When using MG methods, there are two ways to calculate panel long-run parameters from a dynamic model. ${ }^{12}$ First, one applies to Eq. (2) the panel short-run estimates (which themselves are the average of the individual country short-run coefficients). Such an approach is referred to as the long-run average (LRA) and is the most common approach in the literature (standard errors are then computed via the Delta method). The second approach first computes the long-run coefficient for each country (again applying Eq. 2) and then computes the average (of country-long-run coefficients) to arrive at the panel coefficient. This average long-run (ALR) method is closer to the spirit of MG estimations since the panel long-run coefficient is directly based on the average of the individual country long-run coefficients.

In addition to the individual country elasticities being different, there are several reasons why the panel average elasticities for high- and middle-income countries may differ (although given data constraints, e.g., a lack of information on capital stock vintages, it is beyond the scope of the present paper to definitively assess which reason may govern). For example, price elasticities might differ because middle-income countries are more likely to subsidize electricity. Output elasticities could differ because technology differs. And the technology argument could work in either direction: high-income countries could have access to better/more efficient technology, or middle-income countries could have newer capital stocks that are embodied with more technological advances. Additionally, output elasticities could differ if industry structure differs-for example, if industry in middle-income countries is skewed more toward the electricity intensive sectors (like smelting and iron and steel). This last argument follows from the Chang et al. (2019) finding that energy-intensive sectors had higher output elasticities than non-energy-intensive sectors in OECD countries.

The Pesaran (2006) Common Correlated Effects mean group (CCE) estimator accounts for the presence of unobserved common factors by including in the regression cross-sectional averages of the dependent and independent variables, and it is robust to nonstationarity, cointegration, breaks, and serial correlation. The CCE estimator is not consistent in dynamic panels, however, since the lagged dependent variable is no longer strictly exogenous. Chudik and Pesaran (2015) demonstrated that the estimator becomes consistent again when additional $\sqrt[3]{T}$ lags (in our case, 2 , for series with at least 19 years) of the cross-sectional means are included. Hence, we employ the Dynamic Common Correlated Effects (DCCE) estimator of Chudik and Pesaran (2015). ${ }^{13}$ The combination of independent variables, their lags, cross-sectional average terms, and two additional lags of those cross-sectional average terms, means each cross section must

\footnotetext{
12 In both cases, we follow the standard practice of robust regressions (see Hamilton 1992), in which outliers are weighted down in the calculation of averages.

13 The Dynamic Common Correlated Effects estimator of Chudik and Pesaran (2015) is implemented by using Stata command xtmg, which was developed by Markus Eberhardt.
} 
have at least 18 observations for the $\operatorname{ARDL}(1,1,1)$ model; fewer observations are required for the partial adjustment or $\operatorname{ARDL}(1,0,0)$ model. ${ }^{14}$

The DCCE estimator applied to the $\operatorname{ARDL}(1,1,1)$ model, looks like:

$$
\ln E_{i t}=\alpha_{i}+\beta_{i}^{1} \ln \mathrm{VA}_{i t}+\beta_{i}^{2} \ln \text { price }_{i t}+\beta_{i}^{3} \ln \mathrm{VA}_{i t-1}+\beta_{i}^{4} \ln \text { price }_{i t-1}+\beta_{i}^{5} \ln E_{i t-1}+Z_{i t}+\varepsilon_{i t}
$$

where $Z$ represents the cross-sectional average terms. The cross-sectional average terms from Eq. (3) are displayed in Eq. (4) below:

$$
Z_{i, t}=\sum_{l=0}^{2} \rho_{i}^{l} \overline{E_{t-l}}+\sum_{l=0}^{2} \rho_{i}^{l} \overline{\mathrm{VA}_{t-l}}+\sum_{l=0}^{2} \rho_{i}^{l} \overline{\text { price }_{t-l}}
$$

where the bar represents an average over the cross-sections (countries), and $l$ stands for the number of lags.

Dynamic models estimated with panel data are subject to a downward bias, called the dynamic panel or Nickell bias. In the literature this bias is often addressed using the general methods of moments (GMM) estimator (e.g., Cialani and Mortazavi 2018), but GMM was designed for short $T$ panels, and thus, does not necessarily handle nonstationarity. Moreover, since the instrument count increases rapidly with time observations, Roodman (2009) warns that the risk of over-parameterization for GMM is great when $T$ exceeds 10 . In addition, GMM was not intended to manage heterogeneity and cross-sectional dependence. Since downward bias is on the order of 1/T (Nickell 1981), having several time observations can mitigate such bias. Bruno (2005) determined that in unbalanced panels (like ours), the bias declines with average group (cross-section) size (i.e., the bias is not determined entirely by the shortest series). While the shortest cross section has 19 years of data, 59 countries have at least 22 observations, and our average cross-section size is over $30{ }^{15}$ (Again, panel coverage is displayed in Appendix Table 7.)

Energy efficiency improvements do affect energy demand. Indeed, there is a separate literature that aims to model the price-induced and autonomous improvements of the energy efficiency of capital stock (e.g., Sue Wing 2008; Steinbuks and Neuhoff 2014). However, this literature employs substantially different models, methods, and data than the present paper. Some reduced-form demand analyses have included time trends (deterministic or stochastic) to account for this autonomous increase in energy efficiency (e.g., Adeyemi and Hunt 2007; Dilaver and Hunt 2011). The cross-sectional average terms (included in CEE-type estimations) of variables like electricity consumption and output might provide some accounting for energy efficiency improvements (likely

\footnotetext{
14 Both an ARDL(1,2,2) and error correction model were rejected. (Considering even a larger number of lags would mean losing several additional countries from our dataset.)

15 Beck and Katz (2009) claimed that with at least 20 time observations, applying bias correction (e.g., Kiviet 1995) is counter-productive, whereas Judson and Owen (1999) were more conservative, recommending bias correction unless there are 30 time observations. However, Pesaran et al. (1999) cautioned that bias correction to the short-run coefficients can exacerbate the bias of the long-run coefficients.
} 
Table 6 Industry electricity output and price elasticities. High-income vs Middle-income panels

\begin{tabular}{|c|c|c|c|c|c|c|}
\hline \multirow{3}{*}{$\begin{array}{l}\text { Panel } \\
\text { Model } \\
\text { Estima- } \\
\text { tor }\end{array}$} & \multirow{2}{*}{\multicolumn{2}{|c|}{$\begin{array}{l}\text { High-income } \\
\text { ARDL }(1,1,1)\end{array}$}} & \multicolumn{4}{|l|}{ Middle-income } \\
\hline & & & \multicolumn{2}{|l|}{$\operatorname{ARDL}(1,1,1)$} & \multicolumn{2}{|c|}{$\operatorname{ARDL}(1,0,0)$} \\
\hline & MG & DCCE & MG & DCCE & MG & DCCE \\
\hline $\begin{array}{l}\text { Regres- } \\
\text { sion }\end{array}$ & I & II & III & IV & V & VI \\
\hline $\ln E_{t-1}$ & $\begin{array}{r}0.76 * * * * \\
(0.038)\end{array}$ & $\begin{array}{r}0.64 * * * * \\
(0.041)\end{array}$ & $\begin{array}{r}0.64 * * * * \\
(0.056)\end{array}$ & $\begin{array}{l}0.30 * * * \\
(0.094)\end{array}$ & $\begin{array}{r}0.65 * * * * \\
(0.044)\end{array}$ & $0.37 * * * *(0.071)$ \\
\hline $\ln \mathrm{VA}$ & $\begin{array}{r}0.58 * * * * \\
(0.051)\end{array}$ & $\begin{array}{r}0.33 * * * * \\
(0.063)\end{array}$ & $\begin{array}{r}0.66 * * * * \\
(0.084)\end{array}$ & $\begin{array}{c}0.64 * * * * \\
(0.13)\end{array}$ & $\begin{array}{r}0.34 * * * * \\
(0.060)\end{array}$ & $0.64 * * * *(0.089)$ \\
\hline $\ln$ Price & $\begin{array}{c}-0.059 * * \\
(0.026)\end{array}$ & $\begin{array}{c}-0.044 \\
(0.027)\end{array}$ & $\begin{array}{r}-0.028 \\
(0.021)\end{array}$ & $\begin{array}{r}-0.024 \\
(0.050)\end{array}$ & $\begin{array}{c}-0.00092 \\
(0.019)\end{array}$ & $-0.013(0.024)$ \\
\hline $\ln \mathrm{VA}_{t-1}$ & $\begin{array}{c}-0.46 * * * * \\
(0.059)\end{array}$ & $\begin{array}{r}-0.15 * * \\
(0.061)\end{array}$ & $\begin{array}{c}-0.26 * * * \\
(0.096)\end{array}$ & $\begin{array}{r}-0.21 \\
\quad(0.16)\end{array}$ & & \\
\hline $\begin{array}{c}\ln \text { Price } \\
t-1\end{array}$ & $\begin{array}{r}-0.0044 \\
(0.025) \\
\text { Long-run }\end{array}$ & $\begin{array}{r}-0.053^{*} \\
(0.031)\end{array}$ & $0.016(0.022)$ & $\begin{array}{l}0.076^{*} \\
\quad(0.041)\end{array}$ & & \\
\hline \multicolumn{7}{|l|}{$\ln \mathrm{VA}$} \\
\hline LRA & $\begin{array}{l}0.50 \\
{\left[\begin{array}{ll}-0.16 & 1.15\end{array}\right]}\end{array}$ & $\begin{array}{l}0.52 * * \\
{\left[\begin{array}{lll}0.020 & 1.01]\end{array}\right.}\end{array}$ & $\begin{array}{l}1.12 * * * \\
{[0.341 .89]}\end{array}$ & $\begin{array}{l}0.61 * * \\
{[0.040} \\
1.22]\end{array}$ & $\begin{array}{l}0.95 * * * * \\
{[0.541 .35]}\end{array}$ & $\begin{array}{l}1.01 * * * * \\
{[0.651 .37]}\end{array}$ \\
\hline ALR & $\begin{array}{l}0.31 * * * \\
{\left[\begin{array}{lll}0.10 & 0.53\end{array}\right]}\end{array}$ & $\begin{array}{l}0.46 * * * * \\
{[0.260 .65]}\end{array}$ & $\begin{array}{l}1.13 * * * * \\
{[0.831 .43]}\end{array}$ & $\begin{array}{l}1.19 * * * * \\
{[0.791 .59]}\end{array}$ & $\begin{array}{l}1.20 * * * * \\
{[0.921 .47]}\end{array}$ & $\begin{array}{l}1.25 * * * * \\
{[0.971 .54]}\end{array}$ \\
\hline \multicolumn{7}{|l|}{ ln Price } \\
\hline LRA & $\begin{array}{c}-0.26 * \\
{[-0.57} \\
0.039]\end{array}$ & $\begin{array}{l}-0.27 * * \\
{[-0.50} \\
-0.039]\end{array}$ & $\begin{array}{l}-0.033 \\
{\left[\begin{array}{ll}-0.20 & 0.14\end{array}\right]}\end{array}$ & $\begin{array}{l}0.074 \\
{[-0.11} \\
0.26]\end{array}$ & $\begin{array}{l}-0.0026 \\
{\left[\begin{array}{ll}-0.11 & 0.10\end{array}\right]}\end{array}$ & $\begin{array}{l}-0.021 \\
{\left[\begin{array}{ll}-0.097 & 0.055\end{array}\right]}\end{array}$ \\
\hline ALR & $\begin{array}{l}-0.26 * * * \\
{[-0.43} \\
-0.093]\end{array}$ & $\begin{array}{l}-0.25 * * * \\
{[-0.39} \\
-0.11]\end{array}$ & $\begin{array}{l}-0.025 \\
{\left[\begin{array}{lll}-0.26 & 0.21]\end{array}\right.}\end{array}$ & $\begin{array}{r}0.0037 \\
{[-0.21} \\
0.22]\end{array}$ & $\begin{array}{l}0.039 \\
{[-0.079} \\
0.16]\end{array}$ & $\begin{array}{l}0.0024 \\
{\left[\begin{array}{ll}-0.15 & 0.15\end{array}\right]}\end{array}$ \\
\hline $\operatorname{Obs}(N)$ & $1199(35)$ & $1164(35)$ & $786(30)$ & $752(30)$ & $814(30)$ & $752(30)$ \\
\hline RMSE & 0.040 & 0.028 & 0.092 & 0.044 & 0.10 & 0.057 \\
\hline CIPS & $\mathrm{I}(0)$ & $\mathrm{I}(0)$ & $\mathrm{I}(0)$ & $\mathrm{I}(0)$ & $\mathrm{I}(0)$ & $\mathrm{I}(0)$ \\
\hline $\mathrm{CD}$ & $8.0 * * * *$ & $1.7^{*}$ & 1.4 & $-1.9^{*}$ & $-4.0 * * * *$ & -0.2 \\
\hline
\end{tabular}

$L R A$ long-run average, calculated directly from mean group panel results (standard errors computed via the Delta method), ALR average long-run, individual country long-run coefficients are computed from mean group results; panel mean and standard errors are drawn from robust regression (on that series of country results), Obs $(N)$ observations (cross-sections)

Diagnostics: RMSE root mean squared error, CIPS Pesaran (2007) CIPS test on residuals, I(O) stationary, $C D$ Pesaran (2015) CD test statistic on residuals. The null hypothesis is weak cross-sectional dependence $* * * *, * * *, * *, *$ indicate statistical significance at the $0.001,0.01,0.05$, and 0.1 levels, respectively. Standard errors in parentheses. $95 \%$ confidence intervals shown in brackets for the long-run coefficients 
better than deterministic time trends do); such terms also might address several of the concerns raised in (i) Adeyemi and Hunt (e.g., modeling heterogeneous responses to socioeconomic and structural conditions) and (ii) Dilaver and Hunt (e.g., avoiding biased income/output elasticity estimations by not accounting for downward sloping efficiency improvements).

Lastly, in addition to being aggregated over time, the price variable we use only approximates the (sometimes highly) nonlinear electricity tariff schedules that consumers actually face. Ideally, one would want to estimate price elasticities at the marginal tariff, but such data is rarely available. Furthermore, although electricity tariffs are often set exogenously by regulators, some analysts are concerned that price in many aggregate studies is endogenous because price is constructed as average revenue equal to total revenues divided by consumption, which is the dependent variable. Yet, recent evidence suggests that for macro-models, demand elasticity estimates vary little depending on whether an instrument for price was used (Burke and Abayasekara 2018; Csereklyei 2020). However, a related endogeneity issue could occur at the individual sector/firm level since some large industries/firms negotiate prices directly with regulators. Steinbuks and Neuhoff (2014) argued that this potential endogeneity is mitigated when one uses prices that are aggregated at the entire industry/manufacturing sector level (as we do).

\section{Results and discussion}

Table 6 displays the elasticity estimation results. For all the regressions, the residuals are stationary. While those unit root test results for the residuals suggest cointegration, the critical values for panel cointegration tests are stricter than those for panel unit root tests. However, the corresponding statistics from the CIPS tests reported in Table 6 easily exceed the critical values calculated by Banerjee and Carrion-I-Silvestre (2017), who designed a second-generation panel cointegration test that is based on CCE.

In addition, we considered two heterogenous, residual-based first-generation cointegration tests (Pedroni 2004; Westerlund 2005) in which we first subtract the cross-sectional averages from each series (a procedure Levin et al. 2002 recommended to mitigate cross-sectional dependence). The main difference between the Pedroni (2004) and the Westerlund (2005) cointegration tests is that the alternative hypothesis of Pedroni is that all cross-sections are cointegrated, whereas the alternative for the Westerlund test is that some of the cross-sections are cointegrated (the null hypothesis for both tests is no cointegration). The results of both tests (shown in Appendix Table 8) strongly reject the null of no cointegration.

Considering the $\mathrm{CD}$ tests, weak cross-sectional dependence cannot be rejected (at least at standard levels) for the high-income panel (Regression II). Adding the cross-sectional average terms does substantially reduce the CD test static (comparing Regressions I and II). Hence, Regression II would be preferred for the high-income panel, while the test statistic is still marginally significant in 


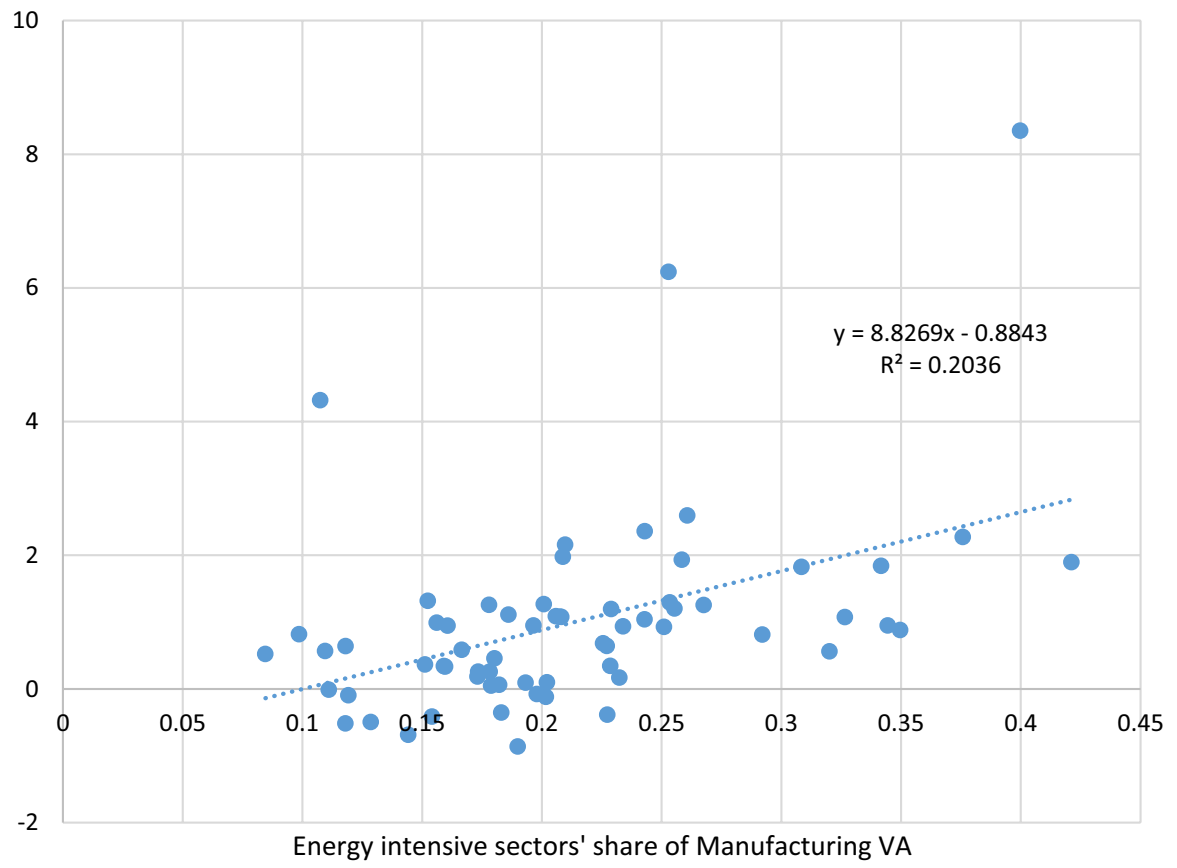

Fig. 5 Individual country long-run value added (VA) elasticity estimates ( $y$-axis) are plotted against the average share of manufacturing value added from the four most energy intensive sectors ( $x$-axis) for the full, 65-country panel (and ARDL $(1,1,1)$ model). Value added data is from UNIDO. Trend line, equation, and $R$-squared also displayed

Regression II, it can be difficult to completely remove evidence of strong crosssectional dependence in OECD panels (see, e.g., Eberhardt and Presbitero 2015; Liddle and Huntington 2020). For the middle-income panel and the ARDL (1, $1,1)$ model, the CD test statistic is similar (in magnitude) for both the MG and DCCE regressions (albeit, marginally significant for Regression IV). For the middle-income panel, a partial adjustment or ARDL $(1,0,0)$ model was run ${ }^{16}$ since contemporaneous price was highly insignificant in the $\operatorname{ARDL}(1,1,1)$ model. For the ARDL $(1,0,0)$ model, DCCE (Regression VI) is clearly superior to $\mathrm{MG}$ since the $\mathrm{CD}$ test implies that strong cross-sectional dependence has been completely removed, whereas for the CD test on Regression V, weak dependence is rejected at the highest level of significance. Yet, for each of the regressions (I-VI) the long-run coefficients for output and price (both the average long-run and long-run average versions) are mostly similar.

The long-run output elasticity for high-income countries is around 0.5 , and is statistically significant (Regression II). In case of the average long-run, the estimate is substantially significantly less than unity. Both long-run output elasticity estimates (long-run average and average long-run) are quite similar to the

16 The ARDL $(1,0,0)$ model was rejected for the high-income/OECD panel. 
earliest OECD panel estimate in which industry energy consumption was the dependent variable-Adeyemi and Hunt (2007). The long-run price elasticities (long-run average and average long-run) for the high-income panel are around -0.25 . These elasticities, both statistically significant, are similar to those of Adeyemi and Hunt and to the European panel estimate of Cialani and Mortazavi (2018), who also focused on electricity demand (and did report their long-run price estimate as being statistically significant).

For the middle-income panel, most of the long-run output estimates are greater than one, and for all cases, unity is well within the $95 \%$ confidence intervals. All of the long-run price elasticity estimates for the middle-income panel are small and insignificant. Considering individual country long-run price elasticities, only about one-half of the middle-income countries had negative elasticities, and only about one-third of those were likely statistically significant. Several middle-income countries subsidize electricity, which would be expected to mute price responses. Indeed, according to the IEA fossil fuel subsidies database (which has data from 2010-2018), 12 countries in our middle-income panel have subsidized/do subsidize electricity. ${ }^{17}$ So, the insignificant middle-income panel long-run price elasticity probably results from a combination of the temporal and sectorial data aggregation and subsidized energy prices. Liddle and Huntington (2020), who focused on economy-wide energy consumption and prices, similarly calculated insignificant price elasticities for non-OECD/middle-income panels (and long-run price elasticities between -0.2 and -0.3 for an OECD/high-income panel).

Comparing the average long-run (ALR) output elasticities for the highincome and middle-income panels, it appears that the middle-income elasticity is statistically significantly larger than the high-income elasticity since none of their confidence intervals overlap. If the middle-income countries have industry structures skewed more towards electricity-intensive sectors than the highincome countries, this finding of a larger output elasticity for middle-income countries would be in line with the recent evidence from Chang et al. (2019), who found a similar difference in energy output elasticities between energyintensive sectors and non- energy-intensive industry sectors based on $O E C D$ panels. Again, on average, it appears that industry is somewhat more electricity intensive in middle-income countries. Also, Figs. 2 and 3 suggest that industry output and electricity consumption were much more aligned in middle-income countries.

To further investigate industry structure's role in explaining the significantly larger output elasticity for middle-income as compared to high-income countries, we create Fig. 5. Figure 5 shows a plot of the individual country (for all 65 countries) long-run value added elasticity estimates (from Regressions II and IV) by the average (1978-2014) share of manufacturing value added contributed by the four most energy-intensive sectors. Those sectors, listed with their

\footnotetext{
17 Those countries are: Algeria, Azerbaijan, Bolivia, Ecuador, El Salvador, India, Indonesia, Iran, Mexico, South Africa, Thailand, and Venezuela.
} 
ISIC Revision 3.1 codes in parentheses, are: chemicals and chemical products (24); non-metallic mineral products (26); and basic metals (27), which includes both iron and steel and non-ferrous metals. ${ }^{18}$ The figure does indicate a positive relationship between the output/value added elasticity and an energy-intensive manufacturing structure (the R-squared for a linear trend line is 0.2 ).

Figure 5 provides some visual evidence that suggests parameter/slope heterogeneity for the output elasticity. Yet, that figure does not indicate whether those elasticities are statistically significantly different from one another. So, to conclude the analysis, we consider several statistical tests of heterogeneity.

First, we determine the number of countries (from each income-based panel) whose long-run (output and price) elasticities are statistically different from the corresponding panel average long-run coefficient (reported in Table 6) at the $10 \%$ level. (For simplicity/consistency we use the $\operatorname{ARDL}(1,1,1)$ model for both the high-income and middle-income country panels, i.e., Regressions II and IV.) For the 35 high-income countries, 17 had output elasticities that were statistically significantly different (at 10\%) from the panel average long-run output coefficient, and seven had statistically significantly different price elasticities. For the 30 middle-income countries, those two counts were 11 and six for output and price elasticities, respectively. If the true individual coefficients were the same as the panel average, one would expect statistically different results because of random error for 3.5 and three countries (from the high-income and middle-income panels, respectively). According to the binomial distribution, producing twice as many statistically different coefficients as expected (as is the case for the price elasticity) has only a 5\% chance of occurring randomly (finding 10 out of 35 or nine out of 30 would have a $0.1 \%$ chance).

Next, we calculate Wald statistics, as suggested by Canning and Pedroni (2008):

$$
W_{\theta}=\sum_{i} \frac{\left(\theta_{i}{ }^{\prime}-\bar{\theta}\right)^{2}}{\operatorname{Var}\left(\theta_{i}\right)}
$$

where $\theta^{\prime}{ }_{i}$ is the country-specific parameter estimate, $\operatorname{Var}\left(\theta_{i}\right)$ is the variance of the country-specific parameter estimates, and $\theta$ is the (unweighted) average of the country-specific estimates. (Again, we use the $\operatorname{ARDL}(1,1,1)$ model, i.e., Regressions II and IV.) This statistic is distributed as Chi-squared under the null that all countries have the same parameter value with degrees of freedom of $N$ (in our case 65). For both output and price elasticities, these statistics (1035 and 178, respectively) strongly reject homogenous parameter values.

\footnotetext{
18 Data on the value added in these sectors is from the United Nations Industrial Development Organization's INDSTAT2 2016 CD-ROM: Industrial Statistics Database. There are missing observations for both countries and particular years.
} 
Finally, we consider a test based on Pesaran and Yamagata (2008) that compares the difference between coefficients obtained by a pooled, fixed effects regression and by a mean-group regression (while adjusting each ARDL (1, 1, 1) regression by adding cross-sectional average terms). ${ }^{19}$ That test (based on the entire 65-country sample) rejects model slope homogeneity at the 0.001 level (delta statistic was 30.5). Separate tests for the high-income and middle-income panels (i.e., Regressions II and VI) also rejected slope homogeneity at the highest level (corresponding adjusted delta statistics were 13.9 and 8.6, respectively).

Hence, it appears that we were correct in assuming/allowing for heterogeneity. Yet, we note that if the true elasticities were the same for all countries, both the mean-group and pooled/fixed effects estimators would be unbiased and consistent, but fixed effects would be more efficient. However, given the presence of nonstationary and cross-sectionally correlated regressors, one might still prefer a mean-group estimator since CCE-MG has been shown to outperform the pooled/ fixed effects version (CCEP) in applications in those areas (see, e.g., Eberhardt and Presbitero 2015; Eberhardt and Teal 2020; Liddle and Huntington 2020).

\subsection{Some policy implications and further discussion}

The output elasticity of around 0.5 for high-income countries suggests that industry has partially decoupled from electricity consumption-i.e., value added can grow at twice the rate of electricity consumption. However, for industry in middle-income countries, value added/output and electricity consumption grow in concert. This finding-particularly with respect to the industrializing, middle-income countries-coupled with the relatively low price elasticities (for both high- and middle-income countries) emphasize the importance of policies that aim to decarbonize electricity (e.g., feed-in tariffs, minimum standards for generation share from renewables) as opposed to policies that are more focused on lowering consumption (e.g., taxes). In other words, a carbon tax, if passed on to end-use customers, may have a limited impact on reducing electricity demand (and thus, lowering emissions).

The relatively large output elasticity for middle-income countries suggests that supply-side authorities/planners need to consider an expansion of the power generation sector. One possible explanation for the different sizes of the output elasticities is that electricity use is more efficient in high-income countries. This explanation opens the possibility for planners in middle-income countries to lower electricity industry demand (and thus avoid electricity generation expansion) via technology transfer (from high-income countries). However, efficiency is an unlikely explanation for two reasons. First, the middle-income countries have electrified more recently, and thus, on average, may have better/more recent vintage technology (of course, subsidizing electricity could lead to inefficient use despite state-of-the-art technology). There is evidence that the current

\footnotetext{
19 That test is run by the Stata command xthst, which was written by Tore Bersvendsen and Jan Ditzen.
} 
economy-wide, energy elasticities of GDP are similar for high- and middleincome countries (e.g., Liddle and Huntington 2020), and that the current such elasticity for middle-income countries is indeed lower than such elasticity for high-income countries was in the 1960s-1970s (Liddle and Huntington 2021a). Second, as we imply in Fig. 5, the higher output elasticity in middle-income countries could be the result of having more energy/electricity-intensive industry structure. Again, Chang et al. (2019) came to a similar conclusion regarding OECD countries and differences between the output elasticity for energy-intensive sectors vs. non-energy-intensive sectors. So, middle-income countries could restructure their industry sectors to be less energy intensive, and thus reduce industry electricity demand (or reduce the need to expand their generation sectors). Of course, unless global demand for electricity intensive products (e.g., aluminum, copper) is reduced, energy/electricity intensive industry would have to locate somewhere.

Two previous electricity demand studies that focused on Europe also considered residential electricity demand. Cialani and Mortazavi (2018) found that residential customers were slightly (but probably not significantly) more sensitive to prices than industry customers (long-run price elasticities of -0.3 compared to -0.2 , respectively). Whereas, Csereklyei (2020) determined the oppositeindustry customers were more sensitive to prices than residential customers (with the long-run residential price elasticity being around -0.5 or half to a third less than industry). If we compare our industry results to the residential electricity demand results of Liddle and Huntington (2021b), for high income countries the price elasticity is nearly the same for industry customers $(-0.25)$ and residential customers (Liddle and Huntington estimated a price elasticity of -0.22 for residential). However, for middle-income countries, residential customers may be more price sensitive than industry customers-Liddle and Huntington (2021b) estimated a significant but small (less than -0.1 in absolute terms) long-run residential price elasticity.

\section{Summary and final conclusions}

There have been relatively few panel estimations of aggregate OECD industry energy demand (although there have been several single OECD country studies). We believe ours is the first such study to (i) employ methods that address heterogeneity and cross-sectional dependence; and (ii) focus on industry electricity demand and estimate both price and output elasticities (i.e., we consider industry output rather than a function of economy-wide output, which can introduce miss-aggregation/alignment bias). Our output and price elasticity estimates of around 0.5 and -0.25 , respectively, are most similar to the earliest OECD panel study Adeyemi and Hunt (2007). However, given that Adeyemi and Hunt focused on energy rather than electricity demand, considered a substantially smaller sample (15 OECD vs 35 high-income countries), and a much different time span (adding years 1962-1977 but not including years 2004-2016), there 
was no a priori reason to expect our estimates would be similar. Our results also are similar to the Chang et al. (2019) estimates for less energy-intensive sectors, but are quite different from their full/all sectors results (Chang et al. considered energy rather than electricity, too).

Much less is known regarding aggregate non-OECD industry energy/electricity demand. We believe ours is the first study to perform panel elasticity estimations of such demand and among the first to consider/analyze non-OECD countries from outside South and West Asia. Indeed, an important advancement in our estimates is the incorporation of time-series data on industry electricity prices for 28 countries outside the IEA/OECD. ${ }^{20}$ When combined with the more widely available OECD prices, this information allows a more reliable estimate of demand by providing an important control variable that separates high-price from low-price periods/countries. For middle-income/non-OECD countries our output elasticity estimations were near unity and likely statistically significantly larger than the output elasticity estimations for high-income/OECD countries.

Our price elasticity for middle-income countries was highly insignificant. Rather than suggesting that industries in middle-income countries are totally unresponsive to price, we believe this finding probably reflects the several high levels of aggregation in our analysis. Electricity price data has been aggregated over time and across both industry sectors and geographic regions; such aggregation likely dampened the estimated price response for both middle-income and high-income panels. Moreover, several middle-income countries in our panel subsidized electricity, which would likewise dampen the price response of electricity consumption. Since this level of aggregation was necessary for data compilation, we reserve a more disaggregated analysis of industry electricity demand across countries for future work.

Finally, we performed several pre- and post-estimation tests (e.g., for unit roots, cross-sectional dependence, cointegration, and heterogeneity). Analysts considering similar variables and models might save time by not replicating all of those tests and instead assuming that nonstationarity, cross-sectional dependence, and heterogeneity are issues worth addressing. Also, our preferred estimation method for addressing those issues-DCCE-is OLS-based; thus, it is no (or not much) more computationally complex than fixed effects, and is substantially simpler/more transparent than other previously employed approaches, such as System-GMM, Structural Time Series Modeling, or Dynamic Multilevel Modeling (which, additionally, may not fully address those three issues).

${ }^{20}$ OECD-middle-income countries Mexico and Turkey have price data available from IEA. 


\section{Appendix}

See Tables 7 and 8 .

Table 7 Data set

\begin{tabular}{llll}
\hline High-income/OECD & \multicolumn{3}{l}{ Middle-income/non-OECD } \\
\hline Australia & $1978-2016$ & Algeria & $1990-2016$ \\
Austria & $1978-2016$ & Azerbaijan & $1997-2016$ \\
Belgium & $1978-2016$ & Bolivia & $1991-2016^{\text {a }}$ \\
Canada & $1978-2016$ & Brazil & $1988-2016$ \\
Cyprus & $1978-2016$ & Chile & $1994-2016$ \\
Czech Rep & $1978-2016$ & Colombia & $1991-2016^{\mathrm{b}}$ \\
Denmark & $1978-2016$ & Costa Rica & $1994-2015$ \\
Estonia & $1995-2016$ & Dominican Republic & $1994-2014^{\mathrm{c}}$ \\
Finland & $1978-2016$ & Ecuador & $1994-2016$ \\
France & $1978-2016$ & El Salvador & $1994-2015$ \\
Germany & $1978-2016$ & Guatemala & $1994-2015^{\text {a,d }}$ \\
Greece & $1978-2016$ & Honduras & $1994-2015$ \\
Hungary & $1980-2016$ & India & $1978-2016$ \\
Ireland & $1978-2016$ & Indonesia & $1978-2016$ \\
Israel & $1995-2016$ & Iran & $1978-2015$ \\
Italy & $1978-2016$ & Jamaica & $1994-2014$ \\
Japan & $1978-2016$ & Jordan & $1990-2016$ \\
Latvia & $1998-2016$ & Lebanon & $1994-2016$ \\
Lithuania & $1995-2016$ & Mexico & $1978-2016$ \\
Luxembourg & $1978-2016$ & Morocco & $1990-2016$ \\
Malta & $1995-2016$ & Nicaragua & $1994-2015$ \\
Netherlands & $1978-2016$ & Panama & $1994-2016$ \\
New Zealand & $1978-2015$ & Paraguay & $1994-2016$ \\
Norway & $1978-2016$ & Peru & $1991-2016$ \\
Poland & $1985-2016$ & Romania & $1995-2016$ \\
Portugal & $1978-2016$ & South Africa & $1978-2016$ \\
Slovakia & $1990-2016$ & Thailand & $1978-2016$ \\
Slovenia & $1995-2016$ & Tunisia & $1990-2015$ \\
South Korea & $1978-2016$ & Turkey & $1978-2016$ \\
Spain & $1978-2016$ & Venezuela & $1981-2014$ \\
Sweden & $1978-2016$ & & \\
Switzerland & $1978-2016$ & & \\
Taiwan & $1981-2016$ & & \\
United Kingdom & $1978-2016$ & & \\
United States & $1978-2015$ & & \\
\hline & & & \\
\hline
\end{tabular}

${ }^{a}$ Missing observation for 2007

${ }^{\mathrm{b}}$ Missing observation for 1993

${ }^{\mathrm{c}}$ Missing observation for 2013

${ }^{\mathrm{d}}$ Missing observation for 2008 
Table 8 Panel cointegration tests, 65 countries, unbalanced

\begin{tabular}{lc}
\hline Pedroni (2004) & \\
Modified Phillips-Perron $t$ & $-12.0^{*}$ \\
Phillips-Perron $t$ & $-25.6^{*}$ \\
Augmented Dickey-Fuller $t$ & $26.7^{*}$ \\
Westerlund (2005) & \\
Variance ratio & $-6.1^{*}$ \\
\hline
\end{tabular}

${ }^{*} p$-value $<0.001$. Null hypothesis is no cointegration. Cross-sectional means have been subtracted to mitigate CSD

Funding No external funding was used in the research.

Code availability Code is available from the authors upon request.

Disclaimer The views represented in the paper are those of the authors and not necessarily of their affiliated organizations.

\section{Declarations}

Conflict of interest The authors declare that they have no conflict of interest.

Data Availability The full dataset used is available from the authors upon request for the purpose of replication.

Open Access This article is licensed under a Creative Commons Attribution 4.0 International License, which permits use, sharing, adaptation, distribution and reproduction in any medium or format, as long as you give appropriate credit to the original author(s) and the source, provide a link to the Creative Commons licence, and indicate if changes were made. The images or other third party material in this article are included in the article's Creative Commons licence, unless indicated otherwise in a credit line to the material. If material is not included in the article's Creative Commons licence and your intended use is not permitted by statutory regulation or exceeds the permitted use, you will need to obtain permission directly from the copyright holder. To view a copy of this licence, visit http://creativecommons.org/licen ses/by/4.0/.

\section{References}

Adeyemi OI, Hunt LC (2007) Modelling OECD industrial energy demand: asymmetric price responses and energy-saving technical change. Energy Econ 29(4):693-709

Adeyemi OI, Hunt LC (2014) Accounting for asymmetric price responses and underlying energy demand trends in OECD industrial energy demand. Energy Econ 45:435-444

Al-Arenan S, Gasim AA, Hunt LC (2020) Modelling industrial energy demand in Saudi Arabia. Energy Econ 85:104554

Alter N, Syed SH (2011) An empirical analysis of electricity demand in Pakistan. Int J Energy Econ Policy 1(4):116-139

Arisoy I, Ozturk I (2014) Estimating industrial and residential electricity demand in Turkey: a time varying parameter approach. Energy 66:959-964

Baltagi B, Pesaran H (2007) Heterogeneity and cross section dependence in panel data models: theory and applications introduction. J Appl Economet 22(2):229-232

Banerjee A, Carrion-I-Silvestre J (2017) Testing for panel cointegration using common correlated effects estimators. J Time Ser Anal 38:610-636 
Beck N (2008) Time-series_cross-section methods. In: Box-Steffensmeier J, Brady H, Collier D (eds) Oxford handbook of political methodology. Oxford University Press, New York

Beck N, Katz J (2009) Modeling dynamics in time-series-cross-section political economy data. In: Social science working paper 1304. California Institute of Technology

Bose RK, Shukla M (1999) Elasticities of electricity demand in India. Energy Policy 27(3):137-146

Bruno G (2005) Approximating the bias of the LSDV estimator for dynamic unbalanced panel data models. Econ Lett 87:361-366

Burke P, Abayasekara A (2018) The price elasticity of electricity demand in the United States: a threedimensional analysis. Energy J 39(2):123-145

Campbell A (2018) Price and income elasticities of electricity demand: evidence from Jamaica. Energy Econ 69:19-32

Canning D, Pedroni P (2008) Infrastructure, long-run economic growth and causality tests for cointegrated panels. Manch Sch 76(5):504-527

Cialani C, Mortazavi R (2018) Household and industrial electricity demand in Europe. Energy Policy 122:592-600

Chang B, Kang SJ, Jung TY (2019) Price and output elasticities of energy demand for industrial sectors in OECD countries. Sustainability 11(6):1786

Chudik A, Pesaran M (2015) Common correlated effects estimation of heterogeneous dynamic panel data models with weakly exogenous regressions. J Econ 188(2):393-420

Csereklyei Z (2020) Price and income elasticities of residential and industrial electricity demand in the European Union. Energy Policy

Dilaver Z, Hunt LC (2011) Industrial electricity demand for Turkey: a structural time series analysis. Energy Econ 33(3):426-436

Driscoll J, Kraay A (1998) Consistent covariance matrix estimation with spatially dependent panel data. Rev Econ Stat 80(4):549-560

Eberhardt M, Teal F (2020) The magnitude of the task ahead: Macro implications of heterogeneous technology. Rev Income Wealth, forthcoming

Eberhardt M, Presbitero A (2015) Public debt and growth: heterogeneity and non-linearity. J Int Econ 97:45-58

El-Shazly A (2013) Electricity demand analysis and forecasting: a panel cointegration approach. Energy Econ 40:251-258

Enders W (2015) Applied time series econometrics. Wiley, Hoboken

Gelman A (2006) Multilevel (hierarchical) modeling: what it can and cannot do. Technometrics 48(3):432-435

Hamilton L (1992) How robust is robust regression? Stata Technical Bulletin 1(2)

Hasanov FJ (2019) Theoretical framework for industrial electricity consumption revisited: empirical analysis and projections for Saudi Arabia. KAPSARC Discuss Pap. https://doi.org/10.30573/ KS-2019-DP66

Hasanov FJ, Mikayilov JI (2020) Energy demand relationship: theory and empirical application. A short note. Forthcoming in Sustainability. https://doi.org/10.20944/preprints202001.0008.v1

Inglesi-Lotz R, Blignaut J (2011) Estimating the price elasticity of demand for electricity by sector in South Africa. S Afr J Econ Manag Sci 14(4):449-465

Islam MK, Merlo J, Kawachi I, Lindström M, Burström K, Gerdtham UG (2006) Does it really matter where you live? A panel data multilevel analysis of Swedish municipality-level social capital on individual health-related quality of life. Health Econ Policy Law 1(3):209-235

Jamil F, Ahmad E (2010) The relationship between electricity consumption, electricity prices and GDP in Pakistan. Energy Policy 38(10):6016-6025

Jamil F, Ahmad E (2011) Income and price elasticities of electricity demand: aggregate and sector-wise analyses. Energy Policy 39(9):5519-5527

Javid M, Qayyum A (2014) Electricity consumption-GDP nexus in Pakistan: a structural time series analysis. Energy 64:811-817

Judson R, Owen A (1999) Estimating dynamic panel data models: a guide for macroeconomists. Econ Lett 65:9-15

Kao C (1999) Spurious regression and residual-based tests for cointegration in panel data. J Econ 90(1):1-44

Kapetanios G, Pesaran MH, Yamagata T (2011) Panels with non-stationary multifactor error structures. J Econ 160:326-348

Khan MA, Qayyum A (2009) The demand for electricity in Pakistan. OPEC Energy Rev 33(1):70-96 
Kiviet J (1995) On bias, inconsistency and efficiency of various estimators in dynamic panel data models. J Econ 68:53-78

Labandeira X, Labeaga JM, López-Otero X (2017) A meta-analysis on the price elasticity of energy demand. Energy Policy 102:549-568

Levin A, Lin C-F, Chu C-SJ (2002) Unit root tests in panel data: asymptotic and finite-sample properties. J Econ 108:1-24

Liddle B, Huntington H (2020) Revisiting the income elasticity of energy consumption: a heterogeneous, common factor, dynamic OECD \& non-OECD country panel analysis. Energy J 41(3):207-229

Liddle B, Huntington H (2021a) There's Technology improvement, but is there economy-wide energy leap-frogging? A country panel analysis. World Dev. https://doi.org/10.1016/j.worlddev.2020. 105259

Liddle B, Huntington H (2021b) How prices, income, and weather shape household electricity demand in high-income and middle-income countries. Energy Econ. https://doi.org/10.1016/j.eneco.2020. 104995

Nickell S (1981) Biases in dynamic models with fixed effects. Econometrica 49:1417-1426

Pedroni P (2004) Panel cointegration: asymptotic and finite sample properties of pooled time series tests with an application to the PPP hypothesis. Economet Theor 20:597-625

Pesaran MH (2006) Estimation and inference in large heterogeneous panels with a multifactor error structure. Econometrica 74(4):967-1012

Pesaran M (2007) A simple panel unit root test in the presence of cross-section dependence. J Appl Economet 22:265-312

Pesaran M (2015) Testing weak cross-sectional dependence in large panels. Economet Rev 34:1089-1117

Pesaran M, Smith R (1995) Estimating long-run relationships from dynamic heterogeneous panel. J Econ 68:79-113

Pesaran H, Shin Y, Smith R (1999) Pooled mean group estimation of dynamic heterogeneous panels. J Am Stat Assoc 94(446):621-634

Pesaran H, Smith R, Akiyama T (1998) Energy demand in Asian developing economies. Oxford University Press for the World Bank and the Oxford Institute for Energy Studies, Oxford

Pesaran MH, Yamagata T (2008) Testing slope homogeneity in large panels. J Econ 142:50-93

Ponce N (2013) Crash course on multilevel modeling. The UCLA center for health policy research. CTSI Clinical Research Development Seminar January 2013

Roodman D (2009) A note on the theme of too many instruments. Oxf Bull Econ Stat 71(1):135-158

Ronfeldt M, Loeb S, Wyckoff J (2013) How teacher turnover harms student achievement. Am Educ Res J 50(1):4-36

Rosenberg N (1998) The role of electricity in industrial development. Energy J 19(2):7-25

Sharimakin A, Glass AJ, Saal DS, Glass K (2018) Dynamic multilevel modelling of industrial energy demand in Europe. Energy Econ 74:120-130

Shirani-Fakhr Z, Khoshakhlagh R, Sharifi A (2015) Estimating demand function for electricity in industrial sector of Iran using structural time series model (Stsm). Appl Econ Int Dev 15(1):143-160

Steenbergen M, Jones B (2002) Modeling multilevel data structures. Am J Political Sci 218-237

Steinbuks J (2012) Interfuel substitution and energy use in the UK manufacturing sector. Energy J 33(1):1-29

Steinbuks J, Neuhoff K (2014) Assessing energy price induced improvements in efficiency of capital in OECD manufacturing industries. J Environ Econ Manag 68(2):340-356

Sue Wing I (2008) Explaining the declining energy intensity of the US economy. Resour Energy Econ 30(1):21-49

van Benthem A, Romani M (2009) Fuelling growth: what drives energy demand in developing countries? Energy J 30(3):91-114

Westerlund J (2005) New simple tests for panel cointegration. Economet Rev 24:297-316 